\title{
Potential universal PCR method to detect decapod hepanhamaparvovirus (DHPV) in crustaceans
}

\author{
Jiraporn Srisala ${ }^{1}$, Dararat Thaiue ${ }^{1}$, Piyachat Sanguanrut ${ }^{1}$, \\ Diva January Aldama-Cano ${ }^{1}$, Timothy W. Flegel ${ }^{2,3}$, Kallaya Sritunyalucksana ${ }^{1, *}$ \\ ${ }^{1}$ Aquatic Animal Health Research Team (AQHT), Integrative Aquaculture Biotechnology \\ Research Group, National Center for Genetic Engineering and Biotechnology (BIOTEC), \\ National Science and Technology Development Agency (NSTDA), \\ Yothi office, Rama VI Rd., Bangkok, Thailand 10400 \\ ${ }^{2}$ Center of Excellence for Shrimp Molecular Biology and Biotechnology (Centex Shrimp), \\ Faculty of Science, Mahidol University, Rama VI Rd., Bangkok, Thailand 10400 \\ ${ }^{3}$ National Center for Genetic Engineering and Biotechnology (BIOTEC), National Science and \\ Technology Development Agency (NSTDA), Thailand Science Park, \\ Klong Luang, Pathumthani, Thailand 12120 \\ *Corresponding author : e-mail address: Kallaya@biotec.or.th
}

\begin{abstract}
Parvoviruses that infect the hepatopancreas (HP) of the penaeid shrimp Penaeus chinensis, $P$. monodon, and $P$. merquiensis were previously called hepatopancreatic parvoviruses (HPV). They are now classified in the family Parvoviridae, sub-family Hamaparvovirinae as members of the same genus called Hepanhamaparvovirus and referred to as decapod hepanhamaparvovirus, designated here as DHPV. However, a virus that causes similar lesions in the HP of the giant river prawn Macrobrachium rosenbergii resembles hepanhamaparvoviruses by microscopy and histochemistry. Unfortunately, no genome information is yet available and PCR detection methods that work for DHPV in P. monodon do not work with M. rosenbergii. For hatchery samples of $M$. rosenbergii in Thailand with DHPV-like lesions, we hypothesized it might be possible to design primer pairs from 8 full DHPV genome sequences at GenBank for use in PCR detection of DHPV in $M$. rosenbergii. Using this strategy, we successfully designed a new set of primers and a PCR protocol called the DHPV-U method that gave an amplicon with DNA extracts from larvae of $M$. rosenberigii samples that showed DHPV-like lesions, while extracts from normal larvae gave none. DNA extracts from P. monodon infected with DHPV also gave amplicons. At the same time, the normal PCR method for DHPV in $P$. monodon gave no amplicon with the $M$. rosenbergii DNA extracts. The DHPV-U amplicons from P. monodon and M. rosenbergii shared $99 \%$ sequence identity, and in situ hybridization (ISH) assays using the DIG-labeled amplicon gave positive histochemical results in the HP tissue of both $P$. monodon and $M$. rosenbergii. The DHPV-U method is now being used in Thailand for detection of DHPV in both P. monodon and $M$. rosenbergii. Overall, the results support the proposal that the HP virus in $M$. rosenbergii is also a
\end{abstract}


hepanhamaparvovirus. Based on $100 \%$ sequence identity of the target region in the currently published DHPV sequences at GenBank, the DHPV-U method may also work for detection of other DHPV isolates.

\section{Keywords}

Parvoviridae; Hamaparvovirinae; Decapod hepanhamaparvovirus; DHPV; Hepatopancreatic parvovirus; HPV; Macrobrachium rosenbergii, Penaeus monodon; PCR detection;

\section{INTRODUCTION}

Parvoviruses that infect the hepatopancreas (HP) of the penaeid shrimp P. chinensis, P. monodon, and $P$. merquiensis were previously called hepatopancreatic parvoviruses (HPV) (Lightner, 1996a). They are now classified in the family Parvoviridae, subfamily Hamaparvovirinae as members of a single species called decapod hepanhammaparvovirus 1 (Pénzes, et al., 2020), abbreviated here as DHPV. There were 8 full sequences listed at GenBank as Hepandensovirus and derived from the three penaeid shrimp species above. However, there is another virus that causes similar lesions in the HP of the giant river prawn Macrobrachium rosenbergii (Anderson, et al., 1990; Lightner, et al., 1994). Preliminary work by electron microscopy and histochemistry (Gangnonngiw, et al., 2009) suggested that the M. rosenbergii virus was also a parvovirus. However, no genome information was available, and it could not be detected using PCR methods designed for DHPV detection in P. monodon (Gangnonngiw, et al., 2009). DHPV was first reported from Thailand in P. monodon specimens (Flegel, et al., 1992) and it has been associated with retarded growth, disease and mortality in juvenile shrimp (Flegel, et al., 1999; Lightner, et al., 1993). However, DHPV (called HPV at the time) was later removed from the OIE list of reportable diseases after analysis showed there was no negative economic effect on the aquaculture industry due to the ability to exclude it from production facilities (Thitamadee, et al., 2016). Although HP lesions similar to those of DHPV in P. monodon, $P$. megquiensis and $P$. chinensis have been reported in other wild and cultured penaeid shrimp species including $P$. esculentus, $P$. japonicus, $P$. semisulcatus, $P$. indicus, $P$. penicillatus, $P$. schmitti, $P$. vannamei and $P$. stylirostris and in the Palaemonid shrimp Macrobrachium rosenbergii (Lightner, 1996b) genome sequence information is lacking, except for a few species (Walsh, et al., 2017), or it is insufficient to determine whether or how closely related they are to DHPV in P. monodon.

The most common diagnostic method that has been used for DHPV detection is histological analysis of the hepatopancreatic tubule cells by H\&E staining to reveal pathognomonic lesions characterized by eosinophilic to basophilic, intranuclear inclusions contained in hypertrophied nuclei of hepatopancreatic tubule epithelial cells (Flegel, et al., 1999; Lightner, et al., 1993). Molecular detection can also be carried out by PCR following OIE standard methods (OIE, 2007) or by using DNA probes for in situ hybridization (Flegel, et al., 1999; Manjanaik, et al., 2005; Phromjai, et al., 2001). However, sensitivity of the methods may vary depending on the host 
species and/or its geographical location due to differences in some portions of the genomes among the DHPV isolates (Dhar, et al., 2014; Phromjai, et al., 2001; Tang, et al., 2008).

81

From 2016-2018, a project to develop specific pathogen free (SPF) M. rosenbergii contacted our research unit to diagnose the cause of unexpected mortality in larvae from a screening program to select a founder stock. The affected larvae showed typical DHPV-like lesions, as had previously been reported (Anderson, et al., 1990; Gangnonngiw, et al., 2009). At the same time, several full sequences of DHPV had accumulated at GenBank, and we hypothesized that, if the virus in $M$. rosenbergii was also a hepanhamaparvovirus, we might be able to design a PCR detection method for it from regions of high sequence identity among the reported isolates of DHPV. Here we report the success of this approach and its confirmation by in situ hybridization analysis. At the same time, analysis of the amplicon sequence supports the proposal that the lesions in $M$. rosenbergii are also caused either directly or indirectly by a hepanhamaparvovirus.

\section{MATERIALS AND METHODS}

\subsection{Shrimp specimens}

Two batches of PLs of Macrobrachium rosenbergii ( 7-14 $\mathrm{mm}$ in length) exhibiting signs of a suspected disease outbreak were obtained in December 2017 and January 2018 from a hatchery in Suphanburi province, Thailand. Batch \#1 (40 PLs 12-14 mm in length) was divided into 2 subgroups: one subgroup (30 PLs) was divided into 3 tubes containing 10 PLs each in $500 \mu$ of TF lysis buffer (50 mM Tris-HCl, $100 \mathrm{mM}$ EDTA, $50 \mathrm{mM} \mathrm{NaCl}, 2 \%$ SDS, $10 \mu \mathrm{g} / \mathrm{ml}$ proteinase $\mathrm{K}, \mathrm{pH}$ 9.0) for DNA extraction, while the remaining 10 were fixed in Davidson's fixative for histological analysis individually in 10 paraffin blocks. Similarly, Batch \#2 (114 PLs 7-10 mm in length) was divided into 2 subgroups: one subgroup (100 PLs) was divided into 10 tubes containing 10 PLs each in $500 \mu \mathrm{l}$ of TF lysis buffer as above while the remaining 14 PLs were fixed with the Davidson's fixative. The fixed PLs were processed for histological analysis in two paraffin blocks containing 7 PLs each. Archived DNA extracts and an archived paraffin block of tissue from $P$. monodon infected with DHPV1 were used for analysis in comparison with the samples from $M$. rosenbergii.

At the time this work was carried out, there was no official standard of the Ethical Principles and Guidelines for the Use of Animals of the National Research Council of Thailand (1999) for invertebrates. However, its principles for vertebrates were adapted for prawn specimens. The guidelines of the New South Wales (Australia) state government for the humane harvesting of fish and crustaceans were followed (http://www.dpi.nsw.gov.au/agriculture/livestock/animalwelfare/general/ fish/shellfish) with respect to processing of the prawns for analysis. The saltwater/ice slurry method was used as recommended in the Australian guidelines. 


\subsection{Histological analysis}

For histological analysis, the living PL of M. rosenbergii specimens were stunned an ice slurry and immediately fixed whole with Davidson's fixative solution overnight before processing for hematoxylin and eosin (H\&E) staining (Bell Lightner, 1988). After that, the hepatopancreatic tissue of each specimen was screened by light microscopy for the presence of DHPV-like lesions. Sections of the same paraffin-embedded tissues were used for in situ hybridization assays.

\subsection{Nucleic acid extraction for PCR amplification}

The 13 M. rosenbergii subsamples of 10 PL each were processed first by removal of eyestalks (to avoid PCR interference) before homogenization in $500 \mu$ l of TF lysis buffer [50 mM Tris-HCl (pH 9.0), $100 \mathrm{mM}$ EDTA, $50 \mathrm{mM} \mathrm{NaCl}, 2 \% \mathrm{SDS}, 10 \mu \mathrm{g} / \mathrm{ml}$ Proteinase K] and incubated for $1 \mathrm{~h}$ at 60$65^{\circ} \mathrm{C}$. Total DNA was purified following the standard phenol: chloroform: isoamyl alcohol protocol (Sambrook Russell, 2001 ) and the DNA pellet obtained was resuspended with $30 \mu 1$ of DNase/RNase free water. Concentration of DNA was determined using a dsDNA BR assays on a Qubit 3.0 Fluorometer (Life Technologies) and stored at $-20^{\circ} \mathrm{C}$ until used.

\subsection{Design of PCR primers}

A new set of primers for DHPV detection was designed base on highly conserved sequences of 8 selected DHPV genome sequences available at the GenBank database (Table 1). The name assigned to this primer set was decapod hepanhamaparvovirus universal primers or DHPV-U primers. The nucleotide sequences of the DHPV-U primers and the existing OIE primers used in the study are listed in Table 2.

Table 1. Nucleotide sequences of complete or almost complete genomes used for multiple sequence alignment analysis for the construction of the DHPV-U primers. The virus names used in the table are those that were used at GenBank at the time of writing. In this article, the penaeid shrimp binomials used are according to Holthuis (1980) and Flegel (2007).

\begin{tabular}{|l|l|l|}
\hline Host Species & Virus name & Accession No. \\
\hline P. monodon & Penaeus monodon hepandensovirus 1 & DQ002873.1 \\
\hline & Penaeus monodon hepandensovirus 2 & JN082231.1, \\
\hline & Penaeus monodon hepandensovirus 3 & EU588991.1 \\
\hline P. chinensis & Penaeus monodon hepandensovirus 4 & FJ410797.2 \\
& Penaeus chinensis hepandensovirus & GU371276.1, AY008257.2, \\
\hline P. merquiensis & Penaeus merguiensis hepandensovirus & DQ458781.4 \\
\hline
\end{tabular}


Table 2. Primers used for PCR amplification in this study.

\begin{tabular}{|c|c|c|c|c|c|}
\hline Method & Primer name & Sequence (5'-3') & $\begin{array}{c}\text { Type of } \\
\text { Reaction }\end{array}$ & $\begin{array}{l}\text { Amplicon } \\
\text { size (bp) }\end{array}$ & References \\
\hline \multirow{4}{*}{$\begin{array}{c}\text { DHPV- } \\
\text { OIE }\end{array}$} & DHPV-441F & GCATTACAAGAACCAAGCAG & \multirow{4}{*}{$\begin{array}{c}\text { Nested } \\
\text { PCR }\end{array}$} & \multirow{2}{*}{441} & \multirow{2}{*}{$\begin{array}{c}\text { OIE } 2007 \\
\text { (Phromjai et } \\
\text { al., 2002) }\end{array}$} \\
\hline & DHPV-441R & ACACTCAGCCTCTACCTTGT & & & \\
\hline & DHPV nF & ATAGAACGCATAGAAAACGCT & & \multirow[b]{2}{*}{265} & \multirow{2}{*}{$\begin{array}{c}\text { OIE } 2007 \\
\text { (Manjanaik et } \\
\text { al., 2005) }\end{array}$} \\
\hline & DHPV nR & GGTGGCGCTGGAATGAATCGCTA & & & \\
\hline \multirow{3}{*}{ DHPV-U } & $\begin{array}{c}\text { DHPV-U } 1538 \\
\text { F }\end{array}$ & сстстTGтTAсАттTтАстС & \multirow{3}{*}{$\begin{array}{l}\text { Semi- } \\
\text { nested } \\
\text { PCR }\end{array}$} & & \multirow{3}{*}{ This study } \\
\hline & $\begin{array}{c}\text { DHPV-U } 1887 \\
\text { R } \\
\end{array}$ & GATGTCTTCTGTAGTCC & & 350 & \\
\hline & $\begin{array}{c}\text { DHPV-U } 1622 \\
\text { F }\end{array}$ & AAGTTTGCACAGTGGTTGT & & 266 & \\
\hline
\end{tabular}

\subsection{PCR methods}

For the DHPV-OIE method, the primers listed in Table 2 by Phromjai et al (Phromjai, et al., 2002)and Manjanaik et al (Manjanaik, et al., 2005) were used, and the reaction was performed following the OIE-manual PCR detection method. For the DHPV-U method, the first step PCR reaction was performed in a $12.5 \mu 1$ mixture containing $1 \mathrm{X}$ OneTaq Hot Start Master Mix (NEB), $0.4 \mu \mathrm{M}$ of each DHPV-U 1538F and DHPV-U 1887R primer and $20 \mathrm{ng}$ of DNA template. The PCR protocol was initial denaturation for $5 \mathrm{~min}$ at $94^{\circ} \mathrm{C}$ followed by 30 cycles of denaturation for $30 \mathrm{~s}$ at $94^{\circ} \mathrm{C}$, annealing for $30 \mathrm{~s}$ at $55^{\circ} \mathrm{C}$ and extension for $45 \mathrm{~s}$ at $72^{\circ} \mathrm{C}$ with a final extension for 5 $\min$ at $72^{\circ} \mathrm{C}$. For the semi-nested PCR step, the $12.5 \mu 1$ reaction mixture contained $1 \mathrm{X}$ OneTaq Hot Start Master Mix (NEB), $0.2 \mu \mathrm{M}$ of each DHPV-U 1622F and DHPV-U 1887R primers and 1 $\mu 1$ of PCR product from the first-step PCR reaction. The PCR protocol was initial denaturation for $5 \mathrm{~min}$ at $94^{\circ} \mathrm{C}$ followed by 25 cycles of denaturation for $30 \mathrm{~s}$ at $94^{\circ} \mathrm{C}$, annealing for $30 \mathrm{~s}$ at $55^{\circ} \mathrm{C}$ and extension for $30 \mathrm{~s}$ at $72^{\circ} \mathrm{C}$ with a final extension for $5 \mathrm{~min}$ at $72^{\circ} \mathrm{C}$. The amplicons were analyzed by $1.5 \%$ agarose gel electrophoresis with ethidium bromide staining and using a DNA ladder marker (2 log DNA ladder from New England Biolabs, USA). Amplicon bands were observed under UV light. The expected amplicons were for light infections one $266 \mathrm{bp}$ band and for heavy infections one $266 \mathrm{bp}$ band plus one $350 \mathrm{bp}$ band. The PCR products obtained were cloned into pGEM-T-Easy vector and subjected to bi-directional sequencing (Macrogen, Korea).

\subsection{Specificity and sensitivity of the DHPV-U method}

To determine the sensitivity of the DHPV-U method, a recombinant pGEM-T plasmid was constructed to contain a DHPV amplicon and it was used as a template at 10-fold serial dilutions in corresponding PCR reactions. The highest dilution that still gave a visible band on the agarose gel was considered the lowest detectable quantity of target DNA, and the equivalent copy number was calculated using Avogadro's number against the molar quantity of plasmid DNA. To determine the specificity of the DHPV-U primer, crustacean samples severely infected with other 
viruses were tested. These included archived DNA and RNA extracted from $P$. vannamei severely infected with either white spot syndrome virus (WSSV), yellow head virus (YHV) or Infectious myonecrosis virus (IMNV), and from P. monodon severely infected with infectious hypodermal and haematopoietic necrosis virus (IHHNV) or Laem Singh virus (LSNV). For WSSV, YHV and IMNV, the IQ2000 kits for detection (GeneReach, Taiwan) of each virus were used. For IHHNV, the levels of infection were determined by the OIE method following Tang et al. (Tang, et al., 2007). For LSNV, the PCR method followed Sritunyalucksana et al., 2006 (Sritunyalucksana, et al., 2006). For the YHV-, IMNV-, and LSNV-infected shrimp, the RNA was extracted and subjected to the Superscript ${ }^{\mathrm{TM}}$ III Reverse transcriptase (Invitrogen, USA) before the cDNA was used as the template for the DHPV-U method. Archived DNA extracts from P. monodon infected with DHPV were also used to compare the DHPV-O and DHPV-U methods.

\subsection{In situ hybridization (ISH) assays using a DHPV-U-derived probe}

The in situ hybridization tests were carried out using paraffin blocks containing DHPV-PCR positive PL of $M$. rosenbergii collected in this study and using archived blocks of DHPV-PCR positive juvenile stages of P. monodon. Digoxygenin (DIG)-labeled DNA probes (Roche, Germany) were generated by PCR according to the manufacturer's instructions. The primers used for the labeling reactions were DHPV-U 1622F and DHPV-U 1887R. The PCR reaction was performed in $25 \mu \mathrm{l}$ containing $0.4 \mu \mathrm{M}$ of each primer, $1 \mathrm{X}$ PCR buffer [200 mM Tris- $\mathrm{HCl}(\mathrm{pH} 8.4)$, $500 \mathrm{mM} \mathrm{KCl}$ ], 1X PCR DIG labeling mix (Roche, USA), $1.5 \mathrm{mM} \mathrm{MgCl} 2,1.25 \mathrm{U}$ Taq DNA polymerase (Invitrogen, USA) and $2 \times 10^{6}$ copies of a plasmid clone containing the DHPV amplicon. The labeled PCR product was purified using a PCR purification kit (Geneaid, Taiwan) and stored in DNase/RNase free water at $-20^{\circ} \mathrm{C}$ until used.

The protocol for ISH was as previously described (Sritunyalucksana, et al., 2006; Tangprasittipap, et al., 2013). Briefly, tissue sections were deparaffinized and rehydrated before being digested with $200 \mu \mathrm{l}$ of $5 \mu \mathrm{g} / \mathrm{ml}$ Proteinase K (Invitrogen, USA) in TNE buffer for $1 \mathrm{~h}$ at $37^{\circ} \mathrm{C}$. The sections were incubated in $0.5 \mathrm{M}$ EDTA at room temperature $\left(\sim 25^{\circ} \mathrm{C}\right)$ for $1 \mathrm{~h}$ before being fixed with ice cold $0.4 \%$ formaldehyde solution for $5 \mathrm{~min}$ and immersed in distilled water for $5 \mathrm{~min}$. The sections were equilibrated with pre-hybridization solution [4 $\times \mathrm{SSC}$ and 50\% (v/v) deionized formamide] at $37^{\circ} \mathrm{C}$ for $1 \mathrm{~h}$. After that, the sections were replaced with hybridization solution containing the DIG-labeled probe (approximately $400 \mathrm{ng} /$ slide) and covered with a coverslip. The control reaction without probe was included in a separate container. The hybridization reaction was incubated at $42^{\circ} \mathrm{C}$ overnight in a humid chamber. After incubation, the sections were washed sequentially for $10 \mathrm{~min}$ with $2 \mathrm{X} \mathrm{SSC}, 15 \mathrm{~min}$ with $2 \mathrm{XSSC}$ at $37^{\circ} \mathrm{C}, 15 \mathrm{~min}$ with $1 \mathrm{XSSC}$ at $42^{\circ} \mathrm{C}$, 15 min with $0.5 \mathrm{X} \mathrm{SSC}$ at $42^{\circ} \mathrm{C}$ and 5 min with buffer I $[100 \mathrm{mM}$ Tris- $\mathrm{HCl}$ and $150 \mathrm{mM} \mathrm{NaCl}, \mathrm{pH}$ 7.5] at room temperature. After washing, the sections were equilibrated with buffer II [Buffer I containing $0.5 \%$ Blocking reagent (Roche, Germany)] at room temperature for $1 \mathrm{~h}$ before incubation with alkaline phosphatase-conjugated anti-digoxigenin antibody (1:500 dilution). The sections were washed 2x10 min with buffer I and equilibrated in detection buffer (100 mM Tris- 
$\mathrm{HCl}$ and $100 \mathrm{mM} \mathrm{NaCl}, \mathrm{pH}$ 9.5). The signal was developed by addition NBT-BCIP substrate (Roche, Germany) in the dark and counterstaining was accomplished with Bismarck brown Y (Sigma, USA). The slides were observed and photographed using an Olympus microscope with a digital camera.

\section{RESULTS AND DISCUSSION}

\subsection{A detection method for DHPV established using DHPV-U primers}

A total of 8 complete or nearly complete genomes of DHPV derived from $P$. chinensis (3), $P$. merquiensis (1) and P. monodon (4) were selected from the GenBank database on 09 September 2018. There were also records for an additional 16 sequences, two of which were redundant to 2 of the 8 selected isolates and 14 that were associated with retracted reports and included a record from $P$. indicus. These sequences are not included in the analysis shown in Fig. 1. Multiple sequence alignment of the 8 selected sequences revealed that sequence identity in many regions were highly conserved at 100\% identity (Fig. 1 and Supplementary Fig. 1). Primers for detection of DHPV were designed from one such region 1538-1556 bp (green), 1622-2640 (blue) and 18711887 (pink), as shown in Fig. 1A. This region also showed 100\% sequence identity in all 14 of the other GenBank sequences not included in the analysis shown in Fig. 1. Theoretically, based on $100 \%$ identity in the target sequence across all the shrimp hosts, the primers should be effective with all 8 of the selected viral types and might also give amplicons with closely related but currently unknown isolates from other species or geographical regions. The locations of the DHPV-U primers in comparison with those used for the OIE method are shown in Figure 1B using the whole genome sequence of DHPV accession no DQ002873.1.

Figure 1. (A) Multiple sequences alignment of 8 DHPV sequences available at the NCBI database, as listed in Table 1 . The conserved nucleotides were indicated by asterisks $(*)$. The highlighted regions were used to design DHV-U primers; DHPV-U 1538F (green), DHV-U 1622F (blue) and DHV-U 1887R (pink). the DHV-U primer sequences and lack of cross reactions with other important viral pathogens of crustaceans. (B) Graphical Primer design from the DHPV-OIE method compared to the DHPV-U method presented in this study. The DHPV sequence belongs to NCBI accession no. DQ002873.1. Red arrows indicate the forward and reverse primer positions.

\section{(A)}

$$
\begin{aligned}
& \text { JN082231.1 } \\
& \text { AY008257.2 } \\
& \text { GU371276.1 } \\
& \text { EU588991.1 } \\
& \text { EU247528.1 } \\
& \text { DQ002873.1 } \\
& \text { FJ410797.2 } \\
& \text { DQ458781.4 }
\end{aligned}
$$

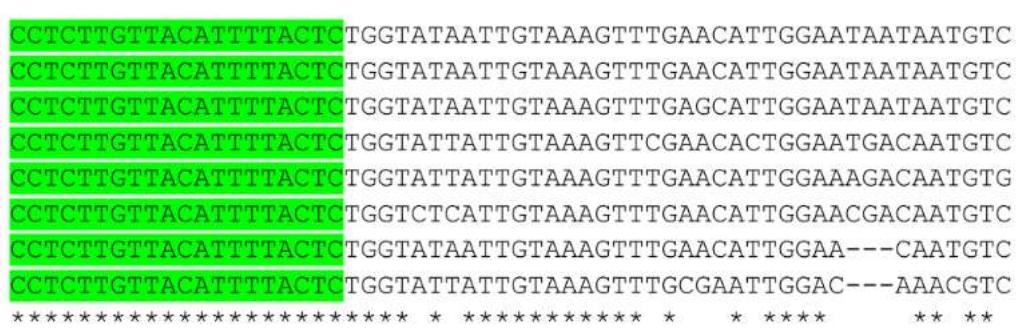

DHPV-U 1538F 
bioRxiv preprint doi: https://doi.org/10.1101/2020.09.01.278721; this version posted September 3, 2020. The copyright holder for this preprint (which was not certified by peer review) is the author/funder. All rights reserved. No reuse allowed without permission.

JN082231.1 AY008257.2 GU371276.1 EU588991.1 EU247528.1 DQ002873.1 FJ410797.2 DQ458781.4

JN082231.1 AY008257.2 GU371276.1 EU588991.1 EU247528.1 DQ002873.1 FJ410797.2 DQ458781.4

JN082231.1 AY008257.2 GU371276.1 EU588991.1 EU247528.1 DQ002873.1 FJ410797.2 DQ458781.4

JN082231.1 AY008257.2 GU371276.1 EU588991.1 EU247528.1 DQ002873.1 FJ410797.2 DQ458781.4

JN082231.1 AY008257.2 GU371276.1 EU588991.1 EU247528.1 DQ002873.1 FJ410797.2 DQ458781.4
AGTAAAGTAAGAAATTTTTGTATAAGTTTGCACAGTGGTTGTATAAGGAATGTACATAC AGTAAAGTAAGAAAGTTTTTGTATAAGTTTGCACAGTGGTTGTATAAGGAATGTACATAC AGTAAAGTAAGAAAGTTTTTGTATAAGTTTGCACAGTGGTTGTATAAGGAATGTACATAC AGTAAAGTAAGAAAGTTTCTGTATAAGTTTGCACAGTGGTTGTATAAAGAATGTACATAC AGTAAAGTAAGAAAGTTTCTGTACAAGTTTGCACAGTGGTTGTATAAGGAATGTACATAC AGTAAAGTAAGAAAGTTTGTGTATAAGTTTGCACAGTGGTTGTATAAGGAATGTACATAC AGTAAAGTAAGAAAGTTTGTGTATAAGTTTGCACAGTGGTTGTATAAGGAATGTACATAC AGTAAAGTAAGAAAGTTTGTGTATAAGTTTGCACAGTGGTTGTATAAGGAATGTACATAC

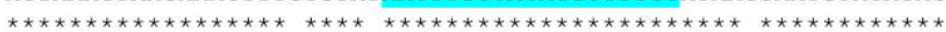

\section{DHPV-U 1622F}

ATCCACAATATAAGTGCCGCAGTTCATGATAGATGTAAAGATGATTGTTGTAAAGACTCA ATCCACAATATAAGTGCCGCAGTTCATGATAGATGTAAAGATGATTGTTGTAAAGACTCA ATCCACAATATAAGTGCCGCAGTTCATGATAGATGTAAAGATGATTGTTGTAAAGACTCA ATCCACAACATAAGTGCGGCAGTTCATGTTAGATGTAATGAAGATTGTTGTAAAGACTCA ATCCACAACATAAGTGCTGCAGTTCATGTTAGATGTAATGATGAATGTTGTAAAGACTCA ATCCACAACATAAGTGCTGCAGTTCATGATAGATGTAAGGATAATTGTTGTAAAGACTCA ATCCACAACATAAGTGCTGCAGTTCATGACAGATGTAAAGATGATTGTTGTAAAGACTCA ATCCACAATATAAGTGCAGCAGTTCATGATAGATGTAATGATAATTGTTGTAAAGACTTA

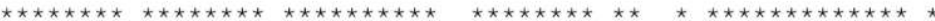

GCCAATAAAGTATGTAAGAACATATATGGTCCTCATTTACACATTTTATTGGAGAGTGTG GCCAATAAAGTATGTAAGAACATATATGGTCCTCATTTACACATTTTATTGGAGAGTGTG GCCAATAAAGTATGTAAGAACATATATGGTCCTCATTTACACATTTTATTGGAGAGTGTG GCCAATAAAGTATGTAAGAACATTTATGGTCCTCATTTACACATTTTATTGGAGAGTGTC GCCAATAAAGTATGTAAGAATATATATGGTCCTCATTTACACATTTTATTGGAGAGTGTC GCCAATAAAGTATGTAAGAACATATACGGTCCTCATTTACACATTTTATTGGAGAGTGTC GCCAATAAAGTATGTAAGAACATATATGGTCCTCATTTACACATTTTATTGGAGAGTGTG GCCAATAAAGTATGTAAGAACATATATGGTCCTCATTTACACATTTTATTGGAGAGTGTG

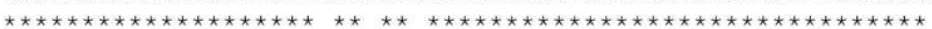

AATGAGAATTGGAGTAAGAGTAGCAAGAGGGTTTTATTCCGCGGCTACGAGAAGATCCTA AATGAGAATTGGAGTAAGAGTAGCAAGAGGGTTTTATTCCGCGGCTACGAGAAGATCCTA AATGAGAATTGGAGTAAGAGTAGCAAGAGGGTTTTATTCCGCGGCTACGAGAAGATCCTA AATGAAAATTGGAGTAAAAGTAGCAAGAGGGTTTTATTCCGCGGCTACGAGAAGATCCTG AATGAGAATTGGAGTAAAAGTAGCAAGAGGGTTTTATTCCGCGGCTACGAGAAGATCCTG AATGAAAATTGGAGTAAAAGTAGCAAGAGGGTTTTATTCCGCGGCTACGAGAAGATACTT AACGAAAACTGGAGTAAAAGTAGCAAGAGGGTTTTATTCCGAGGCTACGAGAAGATCCTG AATGAAAACTGGAGTAAAAGTAGCAAGAGGATTTTATACCGCGGCTACGAGAAGATACTT

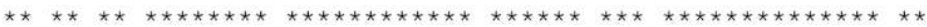

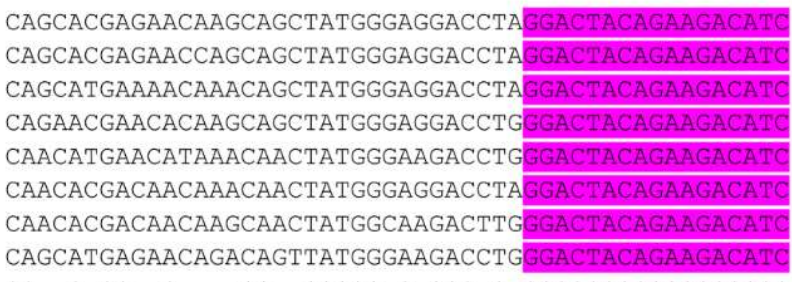

DHPV-U 1887R

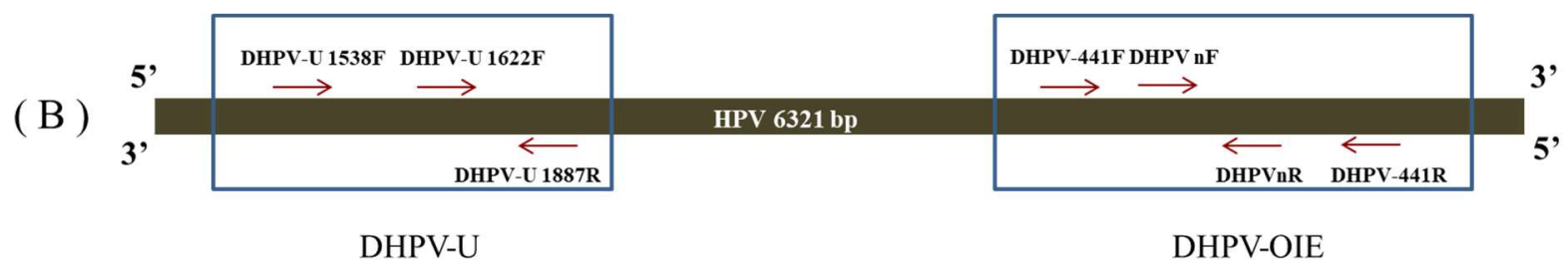




\subsection{Specificity and sensitivity testing of the DHPV-U method} Using the semi-nested DHPV-U PCR protocol with DNA or cDNA templates derived from penaeid shrimp infected with the viruses WSSV, YHV, IMNV, IHHNV and LSNV gave no amplicons (Fig. 2). In contrast, the DNA template from $M$. rosenbergii infected with DHPV gave a positive test result using the DHPV-U PCR protocol (lane 6). The results revealed no cross reactivity of DHPV-U primers with other common shrimp viruses (lanes 1-5).

Figure 2. Specificity testing for the DHPV-U PCR detection method. Agarose gel electrophoresis analyses of the DHPV-U reaction solutions by DNA or cDNA templates from YHV-infected shrimp (lane 1), LSNVinfected shrimp (lane 2), IMNV-infected shrimp (lane 3), WSSV-infected shrimp (lane 4), IHHNV-infected shrimp (lane 5), and DHPV-infected prawn (lane 6). $\mathrm{M}=2 \log$ DNA marker, $\mathrm{N}=$ Negative Control, $\mathrm{P}=$ Positive control. The expected sizes of PCR products amplified by DHPV-U PCR were 266 and $350 \mathrm{bp}$.

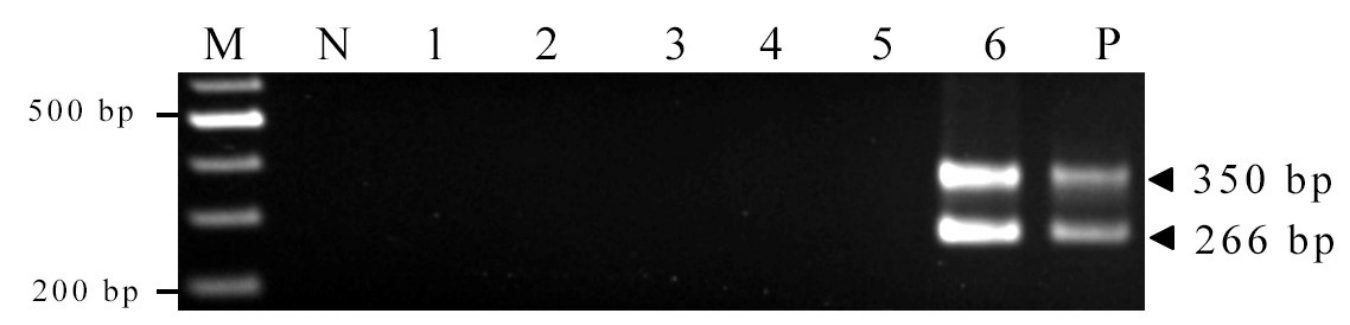

Testing the sensitivity of the DHPV-U method using a serially diluted plasmid template containing a DHPV target $\left(0-2 \times 10^{5}\right.$ plasmid copies per reaction tube) (Fig. 3), revealed that the semi-nested DHPV-U method could detect as little as 2 copies/reaction. A second test was carried out using templates that contained both DHPV-free shrimp DNA (20 ng/reaction) plus DHPV-U plasmid preparation from 0-200 plasmids/reaction. The results (Fig. 3B) show that the lowest copy number of DHPV-U plasmid that could be detected by the DHPV-U method was 50 copies when $20 \mathrm{ng}$ of host DNA was included in the reaction mix. This revealed a strong negative influence of the host DNA on the sensitivity of the DHPV-U method. This effect has been studied and demonstrated in several models (Cogswell et al., 1996; Handschur et al., 2009). Cogswell et al. (1996) demonstrated that host DNA can interfere with specific DNA amplification for Borrelia burgdorferi by PCR and may even lead to false negative results. The sensitivity of pathogen detection is also reduced in next generation sequencing in specimens containing high background human DNA. Several methods have been proposed to solve this problem, including dilution of the template, concentration and extensive washing of the DNA template.

Figure 3. Sensitivity testing for the DHPV-U method. (A) Agarose gel electrophoresis analyses the DHPVU amplicons from PCR using serially diluted DHPV-U plasmid templates at 0 to $2 \times 10^{5}$ plasmids/reaction. (B) Agarose gel showing the effect of host DNA addition (20 ng/reaction) to reactions containing DHPVU plasmid from 0-200 copies. 

(A): without HPV-free
host DNA

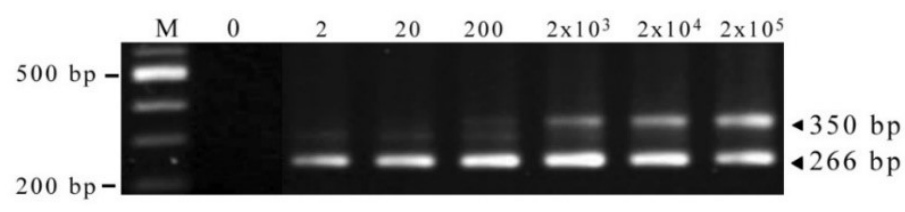

(B): with HPV-free host DNA

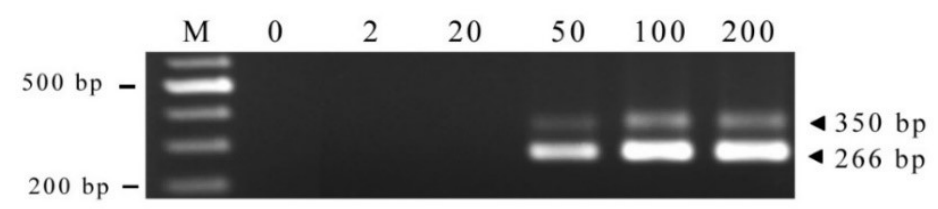

The method compares favorably with the sensitivity of the previously published OIE one-step PCR method (OIE, 2007) and the previously published nested PCR method (Manjanaik et al., 2005) for DHPV in $P$. monodon.

\subsection{Histological analysis of DHPV-infected $M$. rosenbergii}

To confirm the positive PCR results, histological analysis of the affected HP tissue was necessary to confirm the diagnosis since there were no specific gross signs to detect the presence DHPV. Histological examination of tissue sections from the fixed samples of $M$. rosenbergii PL revealed the presence of spherical to ovoid intranuclear inclusions in the HP tubule epithelial cells of some of the specimens. From the first Batch of 10 specimens, only 1 specimen showed typical DHPVlike lesions in the HP. From Batch 2 with 2 slides each with 7 specimens each (total 14), 6 showed DHPV like lesions. An example is shown in Fig 4. These results were sufficient to confirm the PCR results from the 2 batches of shrimp.

The intranuclear inclusions varied in size but were all eosinophilic, characteristic of early stage DHPV lesions (Figure 4, row 1, white arrows). These were similar to the suspected DHPV-like lesions previously observed in samples of $M$. rosenbergii PL and broodstock reported by (Gangnonngiw, et al., 2009). However, in the broodstock, some of the larger inclusions stained basophilic. The fixed hepatopancreas of a P. monodon specimens known to be infected with DHPV were used to compare lesions of similar morphology and staining characteristics in its HP tubule epithelial cells. Example photomicrographs are shown in Fig. 4 (row 1, white arrows).

\subsection{In situ hybridization confirmed DHV infections in $M$. rosenbergii}

To confirm that the DHPV-like histological lesions in the HP of the M. rosenbergii were associated with the positive DHPV-U PCR reactions, in situ hybridization assays were carried out using a DIG-labeled probe derived from a DHPV-U-PCR amplicon. Tissue sections from M. rosenbergii larvae from batches that tested positive using the DHPV-U PCR method and from P. monodon hepatopancreatic tissue known to be infected with DHPV both gave positive in situ hybridization reactions in the nuclei of HP tubule epithelial cells (dark staining against the brown counter-stain) using DIG-labeled probes for DHPV (Fig. 4, row 2). These reactions were at similar intensity and 
in the same tissue areas where the intranuclear inclusions were seen with hematoxylin and eosin 377 (H\&E)-stained, adjacent tissue sections (Fig 4, row 1). No reactions occurred in the control slides 378 processed with no probe present (Figs. 4, row 3).

379

380

381

382

383

384

385

386

387

388

389

390

391

392

393

394

395

396

397

398

399

400

401

402

403

404

405

406
M. rosenbergii
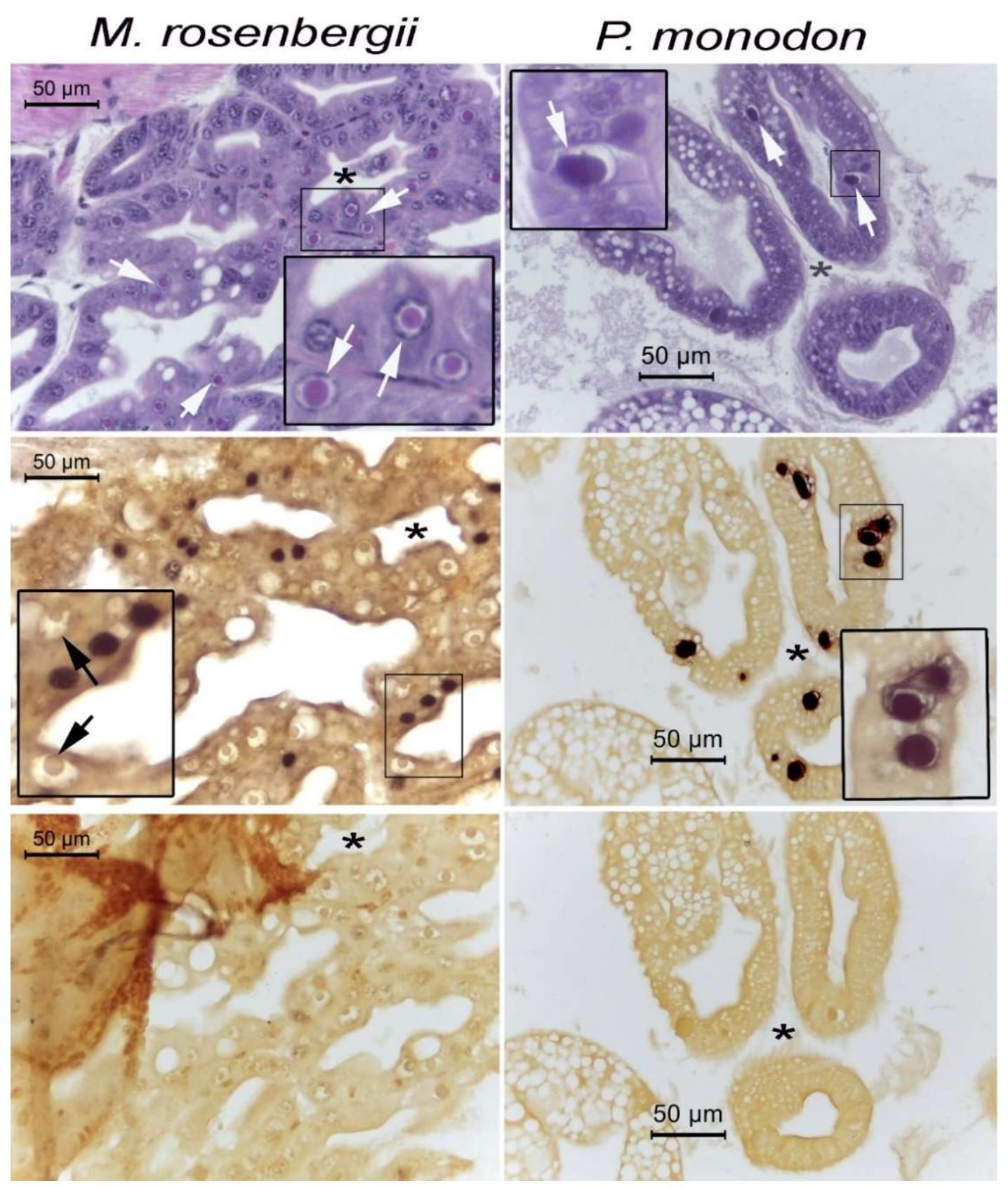

Figure 4. Example photomicrographs of histopathology and ISH reactions with HP tissue of M. rosenbergii and P. monodon. Row 1. H\&E staining showing DHPV-like intranuclear inclusions in tubule epithelial cells marked with white arrows. Inserts show magnified regions. Row 2. Positive ISH reactions (black staining) in locations matching the regions of the intranuclear inclusions in the adjacent sections in Row 1. Row 3. Negative controls for the ISH reactions (no probe). Asterisks in the adjacent tissue sections indicate that same relative position for the photomicrographs in each column. 
Curiously, the positive ISH reactions that occurred in the $M$. rosenbergii specimens did not arise from the intranuclear inclusions associated with DHPV infections but instead in nuclei without such inclusions present. In contrast, the ISH reactions in P. monodon did occur with DHPV inclusions. We have no explanation for this anomaly. We speculate that the inclusion structures or contents in $M$. rosenbergii may prevent hybridization with the probe in some unknown way, such that only nuclei undergoing genomic viral DNA synthesis prior to inclusion formation give positive ISH results. Our attempts to rectify the situation with additional proteinase $\mathrm{K}$ treatment or with sodium hydroxide treatment prior to the ISH reaction did not change the situation. This is curious because earlier work (Gangnonngiw, et al., 2009) showed by confocal laser microscopy that fluorescence from stained nucleic acid in the inclusions was lost or reduced by treatment with DNase 1 or with mungbean nuclease specific for single-stranded DNA, even though the inclusions remained intact. Thus, if the DNase enzyme could penetrate the structure of the inclusions, it is curious that the labeled nucleic acid probe apparently could not and/or was unable to hybridize with the viral DNA. Alternatively, it is possible that DHPV in M. rosenbergii is present in nuclei of normal histological appearance and that the distinctive, eosinophilic to basophilic inclusions arose from some direct or indirect associated cause, although to us this seems unlikely.

\subsection{Comparison of DHPV-OIE and DHPV-U with field samples}

These tests employed 13 DNA extracts from pooled PL samples (10 each) of M. rosenbergii that were suspected of being infected with DHPV and with 11 archived DNA extracts from $P$. monodon infected with DHPV1. When tested for DHPV using the OIE recommended method normally used for detection of DHPV in P. monodon (Fig. 5A), all 13 M. rosenbergii samples gave negative results. When the same DNA extracts were used as templates for the DHPV-U method 11/13 (85\%) (Fig. 5B) gave positive test results. It is possible that the 2 samples of 10 that gave negative results did not contain even 1 PL infected with DHPV, since only 1 of the 10 PLs sampled for histological examination showed DHPV lesions. This indicated that DHPV was not highly prevalent in that batch of PLs such that an occasional sample of 10 might consist of uninfected individuals or might contain a lightly infected individual that yielded too little viral DNA to be detected after mixing with host DNA form 9 other uninfected individuals.

When the DHPV-O and DHPV-U methods were used with 11 archived DNA extracts from $P$. monodon samples that showed DHPV lesions, 11/11 samples gave positive amplicons with the DHPV-O method although the band for sample 11 was very light (indicating a low level infection) and does not show up in photograph in Fig. 5C. The DPHV-U method also gave but 11/11 positive amplicons with the P. monodon samples. This clearly revealed that the DHPV-U method could be used for the different DHPV types in P. monodon and M. rosenbergii.

Next, 5 PCR amplicons (350 bp) from $M$. rosenbergii were arbitrarily selected and subjected to sequencing (Macrogen, Korea) and analysis. All 5 sequences were nearly identical, differing from one another by only 1 or 2 bases, always at different positions (Supplementary Fig. 1). These gave 
a consensus sequence that was used for an nBLAST search against the GenBank database. The top hit of $100 \%$ coverage and $99.4 \%$ identity (311/313 bases, excluding the primers) was for $P$. monodon hepandensovirus 1 (DQ002873.1) (Fig. 6).

Figure. 5. Comparison of DHPV detection in $13 \mathrm{M}$. rosenbergii and $11 P$. monodon samples using the standard OIE detection method or the DHPV-U method. (A \& B) Agarose gel results from using the 2 methods with $M$. rosenbergii samples and showing that the DHPV-OIE method does not work, while the DHPV-U method does. (C \& D) Agarose gel results from using the 2 methods with $P$. monodon samples showing that both methods work with $P$. monodon. $\mathrm{N}=$ Negative control, $\mathrm{M}=2 \log \mathrm{DNA}$ marker and $\mathrm{P}=$ Positive control.

( B ) DHPV-U

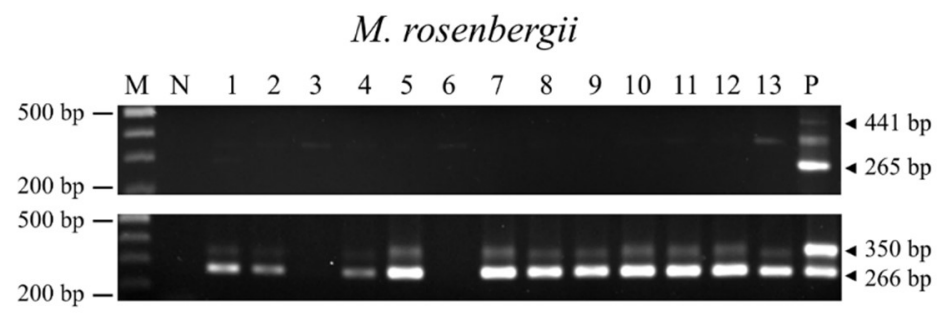

( D ) DHPV-U

\section{P. monodon}

Figure 6. Sequence alignment obtained for the consensus sequence of 5 separate DHPV-U-PCR amplicon clones obtained from $M$. rosenbergii with the matching region of the Blast-n top-hit Penaeus monodon hepandensovirus 1 (DQ002873.1). There are two base differences giving a sequence identity of 348/350= 99.4\%. The first difference (position 48-51) is synonymous for serine while the second (position 163-165) is non-synonymous but is a semi-conserved change from serine to glycine.

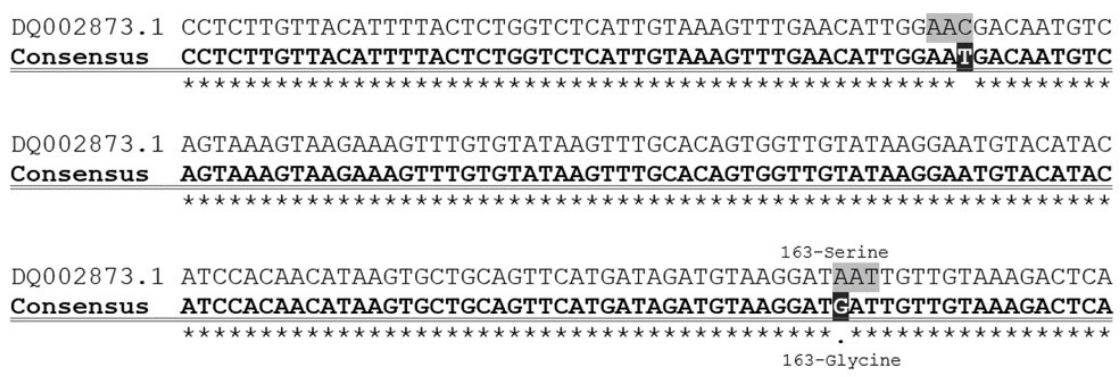

DQ002873.1 GCCAATAAAGTATGTAAGAACATATACGGTCCTCATTTACACATTTTATTGGAGAGTGTC Consensus GCCAATAAAGTATGTAAGAACATATACGGTCCTCATTTACACATTTTATTGGAGAGTGTC

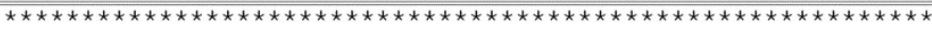

DQ002873.1 AATGAAAATTGGAGTAAAAGTAGCAAGAGGGTTTTATTCCGCGGCTACGAGAAGATACTT Consensus AATGAAAATTGGAGTAAAAGTAGCAAGAGGGTTTTATTCCGCGGCTACGAGAAGATACTT

DQ002873.1 CAACACGACAACAAACAACTATGGGAGGACCTAGGACTACAGAAGACATC Consensus CAACACGACAACAAACAACTATGGGAGGACCTAGGACTACAGAAGACATC 
Overall, the results revealed that the DHPV-U method could be used to screen for DHPV in both $P$. monodon and $M$. rosenbergii in Thailand without any negative consequences in terms of sensitivity or specificity. Indeed, it is somewhat more sensitive than the DHPV-O method at 50 copies when mixed with host DNA compare to 340 for the DHPV-O method (OIE, 2007). Some laboratories have already adopted the DHPV-U method since it provides some convenience when DHPV testing is being carried out with both species. On the other hand, the two methods together would be useful in determining whether the types of DHPV in $P$. monodon and $M$. rosenbergii are cross infective. This could now be determined easily in laboratory studies using the two methods to follow the infections.

\section{Conclusions}

The DHPV-U method described herein can be used to screen for DHPV in both M. rosenbergii and $P$. monodon. Indeed, it is currently being applied for the screening of broodstock and larvae in a program aimed at developing an SPF stock of $M$. rosenbergii in Thailand. It is hoped that such a stock would ultimately provide shrimp farmers with PL free of relevant major pathogens. However, there is still interest in determining the full sequence of the DHPV type or types prevalent in the natural and imported sources of $M$. rosenbergii broodstock that are currently being used in Thailand. Given the high sequence conservation in existing GenBank records for the target sequence of the DHPV-U method, it may be useful in broad, preliminary screening for previously unknown isolates of DHPV in other fresh water, brackish water or marine animals.

Acknowledgements: We would like to thank the financial support from the Royal Society International Collaboration Awards 2019, the Global Challenges Research Fund (GCRF) to Prof. Grant D. Stentiford (Cefas/UK) and Dr. Kallaya Sritunyalucksana (BIOTEC, NSTDA/Thailand).

\section{References} prawn, Macrobrachium rosenbergii. J. Invertebr. Pathol. 55, 447-449.

Bell, T.A., Lightner, D.V., 1988. A handbook of normal shrimp histology. World Aquaculture Society, Baton Rouge, LA.

Dhar, A.K., Robles-Sikisaka, R., Saksmerprome, V., Lakshman, D.K., 2014. Biology, genome organization, and evolution of parvoviruses in marine shrimp, Advances in Virus Research, pp. 85-139.

Flegel, T.W., Thamavit, V., Pasharawipas, T., Alday-Sanz, V., 1999. Statistical correlation between severity of hepatopancreatic parvovirus infection and stunting of farmed black tiger shrimp (Penaeus monodon). Aquaculture. 174, 197-206.

Flegel, T.W., Fegan, D.F., Kongsom, S., Vuthikornudomkit, S., Sriurairatana, S., Boonyaratpalin, S., Chantanachookhin, C., Vickers, J.E., Macdonald, O.D., 1992. Occurrence, diagnosis and treatment of shrimp diseases in Thailand. in: Fulks, W., Main, K.L. (Eds.), Diseases of Cultured Penaeid Shrimp in Asia and the United States. Oceanic Institute, Honolulu, HI, pp. 57-112. 
Gangnonngiw, W., Kiatpathomchai, W., Sriurairatana, S., Laisutisan, K., Chuchird, N., Limsuwan, C., Flegel, T.W., 2009. A parvo-like virus in the hepatopancreas of freshwater prawns Macrobrachium rosenbergii cultivated in Thailand. Dis Aquat Org. 85, 167-173.

Lightner, D., Redman, R., Moore, D., Park, M., 1993. Development and application of a simple and rapid diagnostic method to study hepatopancreatic parvovirus of penaeid shrimp. Aquaculture. 116, 15-23.

Lightner, D.V., 1996a. A handbook of pathology and diagnostic procedures for diseases of penaeid shrimp. World Aquaculture Society, Baton Rouge, LA.

Lightner, D.V., 1996b. A handbook of shrimp pathology and diagnosis procedures for diseases of cultured penaeid shrimp. World Aquaculture Society, Baton Rouge.

Lightner, D.V., Redman, R.M., Poulos, B.T., Mari, J.L., Bonami, J.R., Shariff, M., 1994. Distinction of HPV-type virus in Penaeus chinensis and Macrobrachium rosenbergii using a DNA probe. Asian Fish Sci. 7, 267-272.

Manjanaik, B., Umesha, K.R., Karunasagar, I., Karunasagar, I., 2005. Detection of hepatopancreatic parvovirus (HPV) in wild shrimp from India by nested polymerase chain reaction (PCR). Dis. Aquat. Organ. 63, 255-259.

Pénzes, J.J., Söderlund-Venermo, M., Canuti, M., Eis-Hübinger, A.M., Hughes, J., Cotmore, S.F., Harrach, B., 2020. Reorganizing the family Parvoviridae: a revised taxonomy independent of the canonical approach based on host association. Arch. Virol., 1-14.

Phromjai, J., Boonsaeng, V., Withyachumnarnkul, B., Flegel, T.W., 2002. Detection of hepatopancreatic parvovirus in Thai shrimp Penaeus monodon by in situ hybridization, dot blot hybridization and PCR amplification. Dis Aquat Org. 51, 227-232.

Phromjai, J., Sukhumsirichart, W., Pantoja, C., Lightner, D.V., Flegel, T.W., 2001. Different reactions obtained using the same DNA detection reagents for Thai and Korean hepatopancreatic parvovirus of penaeid shrimp. Dis Aquat Org. 46, 153-158.

Sambrook, J., Russell, D.W., 2001 Molecular cloning:a laboratory manual 3rd Edition. Cold Spring Harbor Press, Cold Spring Harbor.

Sritunyalucksana, K., Apisawetakan, S., Boon-nat, A., Withyachumnarnkul, B., Flegel, T.W., 2006. A new RNA virus found in black tiger shrimp Penaeus monodon from Thailand. Virus Res. 118, 31-38.

Tang, K.F.J., Navarro, S.A., Lightner, D.V., 2007. PCR assay for discriminating between infectious hypodermal and hematopoietic necrosis virus (IHHNV) and virus-related sequences in the genome of Penaeus monodon. Dis. Aquat. Organ. 74, 165-170.

Tang, K.F.J., Pantoja, C.R., Lightner, D.V., 2008. Nucleotide sequence of a Madagascar hepatopancreatic parvovirus (HPV) and comparison of genetic variation among geographic isolates. Dis. Aquat. Organ. 80, 105-112.

Tangprasittipap, A., Srisala, J., Chouwdee, S., Somboon, M., Chuchird, N., Limsuwan, C., Srisuvan, T., Flegel, T.W., Sritunyalucksana, K., 2013. The microsporidian Enterocytozoon hepatopenaei is not the cause of white feces syndrome in whiteleg shrimp Penaeus (Litopenaeus) vannamei. BMC Vet. Res. 9, 139.

Thitamadee, S., Prachumwat, A., Srisala, J., Sritunyalucksana, K., Flegel, T.W., Itsathitphaisarn, O., 2016. Review of current disease threats for cultivated penaeid shrimp in Asia. Aquaculture. 452, 69-87.

Walsh, R., La Fauce, K., Crockford, M., Jones, B., Owens, L., 2017. Genomic heterogeneity and prevalence of hepandensovirus in Penaeus esculentus from Western Australia, and $P$. merguiensis from the Gulf of Carpentaria, Australia. Aquaculture. 471, 43-48. 
bioRxiv preprint doi: https://doi.org/10.1101/2020.09.01.278721; this version posted September 3, 2020. The copyright holder for this preprint (which was not certified by peer review) is the author/funder. All rights reserved. No reuse allowed without permission.

574 